\title{
BMJ Open To see or not to see: a qualitative interview study of patients' views on their own diagnostic images
}

\author{
Leslie E Carlin, ${ }^{1}$ Helen E Smith, ${ }^{2}$ Flis Henwood ${ }^{3}$
}

To cite: Carlin LE, Smith HE, Henwood F. To see or not to see: a qualitative interview study of patients' views on their own diagnostic images. BMJ Open 2014;4: e004999. doi:10.1136/ bmjopen-2014-004999

- Prepublication history for this paper is available online. To view these files please visit the journal online (http://dx.doi.org/10.1136/ bmjopen-2014-004999).

Received 5 February 2014 Revised 27 June 2014 Accepted 30 June 2014
CrossMark

\author{
${ }^{1}$ Department of Physical \\ Therapy, University of \\ Toronto, Toronto, Ontario, \\ Canada \\ ${ }^{2}$ Brighton and Sussex \\ Medical School, Brighton, UK \\ ${ }^{3}$ School of Applied Social \\ Science, University of \\ Brighton, Brighton, UK
}

Correspondence to Professor Helen E Smith; h.e.smith@bsms.ac.uk

\section{ABSTRACT}

Objectives: To ascertain what meaning individuals attach to perceiving images of their own interior body and how the images and their meanings affect the clinical consultation.

Design: Face-to-face semistructured interviews. Participants: 25 adult patients in southern England who, within the preceding 12 months, had been referred for diagnostic imaging.

Setting: Community.

Results: For patients, being shown their own X-rays, MRIs or CT images creates a variety of effects:

(1) a sense of better understanding of the diagnosis;

(2) validation of their sensory and emotional response to the illness or injury and (3) an alteration to the tenor and nature of the clinical encounter between patient and physician. In addition to meanings attached to these images, patients also impute meaning to the physician's decision not to share an image with them. The desire to see their image was greater in those patients with a skeletal injury; patients are less keen on viewing abdominal or other soft tissue images.

Conclusions: Viewing images of one's interior, invisible body is powerful and resonant in a number of ways. The experience of not seeing, whether through the patient's or the physician's choice, is also fraught with meaning.

\section{INTRODUCTION}

Medical imaging is used in healthcare for diagnosis, screening and for monitoring of both disease progression and treatment response. In England alone there were 38805537 imaging investigations conducted in the NHS during 2010/2011. ${ }^{1}$ The armamentarium of imaging techniques has vastly expanded since Roentgen's discovery of X-rays in 1895, and the 'authority of the image' ${ }^{2}$ has also, correspondingly, increased. In the present paper, we begin to explore the meanings imputed to 'still' images when they are shared, or not shared, with patients, and so focus on CT and MRI along with X-rays.

\section{Strengths and limitations of this study}

- There is a paucity of research involving diagnostic imaging in the context of clinical care rather than screening and preventative medicine. In addition, reports of men's perspective on viewing their own diagnostic images are mostly neglected. There has been no previous study exploring patients' reactions to seeing their own diagnostic images in consultation with their doctor.

- Weaknesses include the limited age range of our population; all the adults were 40 years or older, with an average age of 65 years. It would be interesting to find out what a younger generation of patients thinks about the experience of viewing their own medical images.

- The data were collected retrospectively and are thus reliant on participants' recall. We queried only one half of the clinician-patient dyad with respect to the experience of viewing or not viewing a particular image. These physician's own point of view, his or her own reasons for deciding 'to share or not to share', remain opaque to us, reported if at all only by conjecture or hearsay on the part of our research participants.

Development of digital imaging technology enables wider dissemination of images within medicine, and has changed the way these pictures are accessed and used clinically. ${ }^{3}$ The literature on the role of medical imaging techniques concentrates on practitioners and institutions, and largely lacks the patient's viewpoint. A notable exception is the work by Blaxter, ${ }^{4}$ which explores her own experience as a patient looking for conflicting arguments about the ways in which medical technology, and in particular medical imaging, affect the management of illness and of doctor-patient relationships. Blaxter describes how two opposing tropes have prevailed in describing the effects of medical technology on patients. In one the medical image might be seen as the oppressor of the patient, creating a situation in which 'technological representations hide the selves embedded in human bodies'. In this view, patients are rendered passive in 
the face of a technology understood only by the experts; in their turn, medical experts' attitudes toward the preeminence and efficacy of technology is reinforced by their patients' submissiveness to the authority of that technology.

An alternate perspective, propounded by $\mathrm{Mol}^{5}$ and others, argues that rather than being alienated by hightech medical procedures, patients, as well as practitioners, enlist their outputs both to manage their perceptions of themselves and their ailments, and to influence their treatment. Taking this vantage point, the body is not subdued by the image, nor is the patient rendered invisible by it, but rather the body is 'multiplied' to include 'the image as well as the reality'. ${ }^{4}$ Although other works exploring patients and their static images are largely absent, ${ }^{6}$ there has been an interesting thread in the medical anthropology and medical sociology literature exploring the role of women's experiences of particular screening and preventative medicine procedures: screening mammography, ${ }^{7}$ antenatal fetal ultrasound $^{8-11}$ and bone densitometry. ${ }^{12-15}$ Unfortunately, this research has not extended into the context of general clinical care, and has neglected the perspectives of men.

In a previous project, we queried general practitioners (GPs) and consultant radiologists about the impact of sharing medical images with patients during consultations, and about the role of Picture Archiving and Communications technology on the dissemination of diagnostic radiographic images beyond the hospital and into the arena of primary care. ${ }^{3}$ In this study, we shift the focus to the 'third leg' of the radiologistclinician-patient tripod: the patient. Two central questions are addressed: (1) What meanings do individuals attach to perceiving images of their own interior body? and (2) How do the images, and their meanings, affect the clinical consultation?

\section{METHODS}

\section{Participants and sampling}

Twenty-five patients from nine general practices in the south-east of England participated in this study (table 1). A convenience sampling strategy was used, participants were recruited by 11 GPs who during the consultation enquired of the patients' willingness to participate in a semistructured interview concerning their experiences of a recent referral from general practice for diagnostic imaging (X-ray, CT or MRI). We focused on these modalities as they produce a static image that is viewed separately, as opposed to the dynamic procedure of ultrasonography (cf. ref. 6). The study inclusion criteria were adult, fluent speaker of English, competent to

Table 1 Characteristics of interviewees $(n=25)$

\begin{tabular}{|c|c|c|c|c|}
\hline Study ID & $\begin{array}{l}\text { Age at } \\
\text { interview (years) }\end{array}$ & Reason given by patient for imaging referral & $\begin{array}{l}\text { Patient saw } \\
\text { focal image }\end{array}$ & $\begin{array}{l}\text { Has seen other } \\
\text { medical images }\end{array}$ \\
\hline $\mathrm{F} 1$ & 59 & Abdomen and chest X-rays (diverticulitis) & No & Yes \\
\hline $\mathrm{F} 2$ & 81 & Swollen knee X-ray & No & Yes \\
\hline F3 & 49 & Broken thumb X-ray & Yes & Yes \\
\hline M4 & 83 & Swollen ankle X-ray & No & No \\
\hline F5 & 44 & Head and neck MRI & Yes & Yes \\
\hline F6 & 46 & Hip X-ray & Yes & Yes \\
\hline M7 & 62 & Chest X-ray & No & Yes \\
\hline M8 & 76 & Hip X-ray & Yes & Yes \\
\hline F9 & 49 & Chest X-ray (possible metastasis) & Yes & Yes \\
\hline F10 & 72 & $\begin{array}{l}\text { Chest/lung X-ray and CT fragility fracture leg, } \\
\text { collarbone, X-ray and CT }\end{array}$ & Yes & Yes \\
\hline F11 & 55 & $\mathrm{MRI}$ & Yes & Yes \\
\hline F12 & 71 & Spine; X-ray & No & Yes \\
\hline F13 & 41 & Back; X-ray and MRI & Yes & Yes \\
\hline M14 & 49 & Chest X-ray & Yes & Yes \\
\hline F15 & 74 & Back and torso X-ray & No & Yes \\
\hline M16 & 53 & Neck and shoulders; X-ray & No & Yes \\
\hline M17 & 83 & Spine; X-ray & Yes & Yes \\
\hline M18 & 86 & Chest X-ray, MRI & No & Yes \\
\hline F19 & 65 & Mammogram & Yes & Yes \\
\hline F20 & 48 & Neck X-ray & Yes & Yes \\
\hline M21 & 74 & Hip X-ray & No & Yes \\
\hline F22 & 84 & Chest and foot X-ray & No & Yes \\
\hline F23 & 78 & chest X-ray & Yes & Yes \\
\hline M24 & 72 & Hip and spine X-ray and MRI & Yes & Yes \\
\hline F25 & 75 & Arm X-ray & No & No \\
\hline
\end{tabular}

$\mathrm{F}$, female; $\mathrm{M}$, male. 
consent and had been referred to an outpatient imaging department within the past 12 months.

\section{Interview procedure}

Written consent was gained prior to beginning the interview, which was audio-recorded and professionally transcribed. All interviews were conducted by LEC, an anthropologist by training. Topics included patients' experiences of undergoing an imaging procedure, their attitudes toward the viewing or not viewing the resulting images, and their beliefs and opinions concerning the place of such images in a clinical consultation. Descriptive (interview setting, participant behaviours) and reflective field notes were made during the interview process.

\section{Analysis}

Data were analysed following a qualitative descriptive method. ${ }^{16}$ All transcripts were read and coded by two researchers (LEC and HES), manually by both researchers, and using a computer-assisted qualitative data analysis program (NVivo) by one researcher (LEC). Data were coded 'freehand' by creating as many new free nodes as seemed necessary, and then 'rolling up' nodes into hierarchies or trees. The freehand and the electronically assisted coding produced very similar results.

\section{RESULTS}

Twenty-five of 47 patients who expressed initial willingness to participate were interviewed; two potential participants changed their minds and the remainder were uncontactable, ineligible or unavailable within the time frame of the project. Participants ranged from 41 to 86 years (mean age 65 years); nine $(36 \%)$ were men. At the request of the ethics committee we did not count or collect information about the participants who declined the GPs invitation to participate. Most of the interviews were conducted in the participant's own home, but three individuals wished to be interviewed on university premises. Interviews ranged from 13 to $52 \mathrm{~min}$, with a mean of $28 \mathrm{~min}$.

Although the patients were recruited on the basis of having undergone a recent diagnostic imaging procedure, sometimes other experiences of imaging also formed part of the discussion, for example earlier imaging experiences of themselves or others. Of the 25 participants, $14(56 \%)$ reported having been shown the image that rendered them eligible for this study, and 23 (92\%) spoke of how on some other occasion they had viewed images of themselves or of relatives (children, parents, spouses) (table 1). In the results, to preserve anonymity, we use a convention of numbering participants, prefixed with ' $\mathrm{M}$ ' to indicate a male and ' $\mathrm{F}$ ' a female participant.
What the images mean to patients

Patients' opinions, wishes and thoughts on images 'being shared with' varied, as did the meanings they took away from the experience-or the lack of the experience-of viewing their own interior. The themes that emerged from our coding formed three identifiable but interwoven strands, namely that being shown images (1) enhances understanding of the problem, (2) affects the emotional impact of diagnosis and (3) changes the nature of the interaction with the physician during consultation.

First, the patients who viewed their own images reported that doing so enhanced their understanding of their ailments. Seeing the image informed; it served as a visual aid in a basic pedagogical sense. In addition (one thread) the image also validated sensation-'that's why it hurts like it does' (participant F13). In either case, the result of seeing the image produced or enlarged knowledge by the patient of her own corpus, it linked body to mind; several respondents commented that pain seemed easier to manage once they had seen its source 'for themselves'. F13 continues:

I think it was easy because then when he [physician] was talking about it and he could actually kind of point and see, so when someone is saying about the bottom disc missing from your spine you've got a vague idea of kind of where that is, but when you can actually look at it and he's pointing and showing you the different bits, and I think it actually helps you understand, it's not just some kind of airy fairy thing, it's actually there in front of you, and you can see it, and I think that's got to be a good thing.

F3 concurred, saying '.. if I had any fractures in the future I would want to see the fracture because I think it helps you understand the pain, if that makes sense...He [the consultant] wasn't hugely informative but I think the x-ray picture said it all.' In some cases, the expectation of knowledge emanating from the image was very high indeed, and possibly unrealistic in its reach: '...If I was able to see the x-ray I might have been able to see something that, you know, where the pain is, and say to the doctor "Well that's where I'm getting this pain, that area there." And they might be able to either explode that image up and see if there is anything in that actual area'. (M16)

In a second theme, viewing the image had an emotional impact, generally one of reassurance, and not necessarily reliant on greater comprehension of the medical facts of the case. For instance M8 described viewing an image of his lungs: "I think this a modern sort of thing isn't it now? Where patients get to see X-rays. Good thing for settling you down and making you feel calmer I think, and being aware that there's nothing wrong. I mean most people haven't got any medical knowledge at all have they, to be quite honest. So they could have been sideways, upside down, I wouldn't have known the difference." Participants often spoke of the importance of 
having trust or faith in the physician, whether GP or specialist, as being more important than seeing the image on which the doctor based his or her diagnosis or treatment recommendation: "I've got faith in them, that their expertise is better than me looking at their pictures" (M8). Nonetheless, seeing the image for oneself offered reassurance for some participants. F23, commenting on a recent spinal X-ray, remarked: "I was relieved that I could see definitely having had it pointed out to me, what was wrong, and it wasn't anything that I could have avoided myself, that it was just the bones had come together, trapped the nerves, that was it, and I could see for myself what had happened." Other participants, however, felt added anxiety, as opposed to reassurance, about seeing an image that could convey bad news; for instance, a participant being investigated for possible lung cancer, F9, commented, "I think it's a very grey area to want to see the X-ray if you don't know what you are looking for ..." M21 expressed a quite certain opposition to viewing his hip X-ray: “... no, I don't think so, no, no, I don't want to look at it, I don't think so. I mean I don't want to see it to be honest ... If it's bad I don't want to see it, you know, I can feel that it's not good, I know it's not good so I'll take that as evidence."

Finally, the third thematic strand in our analysis focuses on the impact of shared viewing of the medical image as changing the nature of the consultation with the physician. Again, this theme comprises multiple threads. In one, we elucidate the manner in which the physical presence of the image serves as a focal point for both doctor and patient, changing the consultation dynamic. An example: F6, discussing her hip and lower spine X-ray, enthused, "but to actually see it as a patient I think is invaluable really, I think it would be marvellous, and also in terms of mediating the relationship with your doctor because we're talking about a third thing, rather than it being ... face to face ..." This patient, an articulate woman familiar with medical argot and medical practitioners, finds comfort in having the image serve as a point of common interest, rather than she, as the patient, being the sole focus of the medical gaze. For other participants, the image almost becomes a third 'actor', more than a 'thing', within the room, exemplified by several quotes beginning "The X-ray says"; for instance, "[T] he X-ray says arthritis" (M24). The image, however, may attract the attention of the physician at the expense of the attention paid to the actual patient in the room, or, as in the case of participant M24, give the impression that the physician's opinion is at odds with the diagnosis 'made' by the image: "I could tell he didn't quite agree with this X-ray. But he didn't say that. They don't say, 'I don't agree with it."”

The very decision made by the physician as to whether to show the image to the patient affects the way the patient understands the relationship between themselves and the doctor. Respondents with whom the doctor had deliberately shared an image felt more part of the consultation, and sometimes of the treatment decisions. They also felt more respected and valued by their doctor, both because to share the image took more time than not to, and because the expectation of interest, even without comprehension, in the anatomical facts suggested that the doctor had a high opinion of the patient as a person. The act or fact of sharing implied respect and concern "... because you feel they've taken the time to show you. You feel they care a lot" (M24). F1, suffering from an abdominal complaint, commented:

I suppose it would be- yes, very sort of empowering in a kind of way if somebody had time to say "This is the $\mathrm{X}$-ray, this is the thing we found, this is where the disintegration is but this bit's all right." I think yes it would be good, but I think it would so far exceed my expectations because of the lack of time that people have that it wouldn't even come into my head to think that it might be possible.

M16 talks about his experience of seeing X-rays of his hip and shoulder, saying "I think it brings you a little bit closer to the doctor and a bit more rapport with them. That's what I just feel." However, the effect of the clinician's decision about shared viewing of an image is perhaps conveyed most clearly by the comments of participants whose doctors chose not to share with them an image which the doctor was currently scrutinising. M24, speaking of his hip and spine X-ray, said "[In]... fact I didn't ask because I don't think I'd know anything about it anyway. I wouldn't know anything on the X-ray. He could tell me, but I just felt-I didn't ask, so he wasn't going to show it." This respondent had caught a brief glimpse of the image on the doctor's monitor, which the doctor gazed at during the consultation, "It's white, it's a light, it attracts your eye." This respondent disparaged his own intelligence when trying to explain why his doctor denied him a look at the image himself: "I guess he has pressure, his other patients. And, but yes, he's very good. He would answer any questions I asked him. It's only our ignorance that we don't know what to ask..." From our interview, it is clear that this man had wit enough to ask thoughtful questions about his spinal disc problem and in response to a question about why he wanted to view the image, he replied, "I suppose it makes you feel a little bit more involved, a bit more interested, or a bit more involved in what's going on inside you, because it is your body. They would be sort of, kind of added extras. I could have come out and said, 'Do you know what, they've showed me my back'." Another respondent, F9, reported noticing a CT image of her kidneys on the monitor on her doctor's desk. "And I was sort of looking at it, and he went 'Oh, that's not for you to see' and turned the screen, the computer screen [away]." Other respondents expressed concern about the added time it would take a doctor to show and explain the image. F22 felt that she would like to 
view images of her foot X-ray, but commented: "It would be interesting yes, but I would think it's a time factor with lots of doctors having to stop and show people and explain everything." M24 concurred with respect to his lower back and pelvic image:

If he had shown me the X-ray and I could have been a person that wanted to know every little detail of it and it could have been five, ten minutes explaining. But he's got a pressure of a queue outside waiting to come in.

\section{Variation and trends in responses}

Many participants (12/25) provided mixed responses about wanting to view their images, they wanted and appreciated the opportunity to view some images but not others. However, six participants were unambivalently in favour of viewing their images, while five participants did not ever wish to see them. Two participants had never seen their own images said they would have liked to have had the opportunity. No particular pattern emerged regarding preference and age or sex, but we found a trend with respect to anatomy: patients were more eager to view pictures of the skeleton, whereas soft tissue, especially abdominal organs, elicited a higher level of squeamishness and a reduced desire to view the image. F11 expressed huge enthusiasm about viewing X-rays of her spine, but added, "I'm not saying I'd want to look at my own tummy, you know, but to look at an X-ray is brilliant"-X-ray clearly connoting 'bones' to her. On the other hand, our pilot interviewee, who was not recruited from primary care, commented that bony $\mathrm{X}$-rays serve as a reminder of mortality, in contrast to, for instance, antenatal ultrasound, which this respondent characterised as being 'completely different', and 'about life'. The desire or lack of desire to see one's own image was also linked for some with the seriousness of the ailment, or the danger of planned procedure. One participant, F23, discussed her examination for two ailments, one respiratory and one spinal. She feared the effects of her spinal problem more than her respiratory complaint and thus felt a greater desire to view for herself the image of her spine: “...I wasn't worried about wheezing with my chest, I mean I know it could be serious, but I didn't think it was serious, but I was very worried about my spine because I was worried I would be like it for the rest of my life..."

Those participants who did not want to see the image felt that shared viewing the image was a waste of time, their own and that of the clinician. F20, who had undergone a neck X-ray for persistent pain, probably arthritic, felt only added frustration at viewing the image in the company of the specialist nurse-practitioner: “...no, I mean if you don't know what you're looking at then it's not really very helpful is it." She said that had it been an image of her child she would have certainly wanted to see the image. F2, aged 81, consulted her GP for a problem with her spine, and also discussed an experience getting an X-ray for a foot injury. She felt that it might be 'interesting' to see the image, but went on to say

Well really you rely on the doctor don't you to advise and you just go along with that, so you're hoping that you're getting the right medication ... I mean they've been through all their learning haven't they, and degrees and such like, and they know better than I do, hopefully.

F3, who felt strongly that she better understood and dealt with her pain from a fractured thumb because she had viewed the X-ray herself, also commented on the importance of trusting the doctor, who told her he was 'happy with the positioning of the fracture'. The positioning as viewed on the X-ray did not look right to F3, who said “...We were slightly confused ... but you're trusting that the doctor knows what he's talking about, so that was really it, that was basically what he said..."

\section{DISCUSSION}

\section{Statement of principal findings}

While clinicians order diagnostic imaging with the aim of adding to their information about a patient's complaint, the images themselves and their production, do more than convey clinical data. For our research participants, adults aged 40 and above living in the south of England who had recently undergone diagnostic imaging, the static medical image occupies multiple positions: it enhances the patient's understanding of his or her complaint; it has the potential for emotional impact (positive and negative), and it affects the nature of the doctor-patient encounter. The three themes identified in the data highlight the symbolic meanings attaching to the act of viewing the images alongside the doctor: (1) greater comprehension of the illness or injury; (2) the emotional effect linked to viewing one's 'invisible body' and (3) the influence of shared viewing of the image on the social dynamic of the medical consultation.

\section{Strengths and weaknesses in relation to other studies, discussing important differences in results}

Unlike other studies this investigation included both men and women, and took a patient-centred perspective focusing on the process of sharing images in a clinical consultation, rather than taking a medicalised, illnesscentric stance enquiring about a particular ailment or procedure. Previous research has focused on diagnostic subgroups and specific technologies (eg, older women and bone densitometry ${ }^{12}$; pregnancy and ultrasound, ${ }^{17}$ mammography $^{18}$ and hysteroscopy ${ }^{19}$ ). All of these studies focus on women, but $\mathrm{Cohn}^{20}$ explores neurological or psychiatric patients understanding of their brain scans. Radstake ${ }^{6}$ conducted what she calls 'endography' (ie, an inner-looking take on 'ethnography') of patients undergoing real-time imaging in a Dutch hospital. A recurrent theme in this stream of literature is a sense of patients' discomfort with the imaging and with 
technology more generally. Reventlow et $a l^{13-15}$ working with Danish women in their 60s, noted that the highly technological nature of the investigation created in these asymptomatic women a sense of weakness and vulnerability. Griffiths $e t a l^{18}$ explored women's perspectives on breast screening and mammogram, again finding that the visualisation technology imposes on women a devaluation of their own breast and body awareness, 'separating the at-risk breast from embodied experience'. Our work, however, suggests that for some patients, in some situations, viewing their own images generates an almost opposite reaction, one of enhanced empowerment and of reassurance.

Van Dijck ${ }^{21}$ writes that 'patients often blindly trust the panoptic nature of the mechanical-clinical eye'. In this study, we find otherwise; patients are neither blindly trusting nor entirely certain of the role of the image in clinical care, but are, like their doctors, finding their way through the information available to the best possible solution for them. Merleau-Ponty ${ }^{22} 23$ argues that perception is an embodied experience; that viewing images, in the case of one's self, becomes incorporated into the individual's sense of himself or herself. Cohn ${ }^{24}$ reports that patients who chose to view images from their brain scans regarded the image as validating the sensation, the experience of mental illness. Where other forms of communication such as reports and numerical data seem inaccessible, and perhaps inapplicable, the picture itself embodies and thus represents in a simple and, according to Cohn, 'autonomous' manner the mental illness and consequent suffering of that particular patient. In the present study, we have explored the role of the image in dealing with physical illness and injury.

\section{Meaning of the study: possible explanations and implications for clinicians and policymakers}

Our own previous research suggests that physician opinion about sharing images with the patients varies, and that the reasons for the decision 'to share or not to share' range from the logistic to the philosophical. $\mathrm{Mol}^{5}$ writes that X-rays are performed 'one body at a time'; our aim in this project has been to understand the perspectives of people whose bodies, one at a time, were investigated. We have described both positive and negative attitudes of these respondents towards seeing images of the interior body. These affective responses around the viewing of images, however, are not uncomplicated or unmitigated; more cognitive considerations also come into play, including which part of the body has been imaged, the nature of the ailment and indeed the nature of the patient. Thus, we cannot reach simple conclusions or make recommendations as to whether and when sharing images with patients promote a good outcome.

\section{Limitations of our study}

Weaknesses include the limited age range of our population; all the adults were 40 years or older, with an average age of 65 years. It would be interesting to find out what a younger generation of patients thinks about the experience of viewing their own medical images. The data were collected retrospectively and are thus reliant on participants' recall. The number and characteristics of patients who were eligible for inclusion in this study but declined to participate are not available to us; this was a condition of the research ethics committee approval. Finally, the study was based in the UK where the availability of medical images in the clinical setting may differ from other countries. In the UK, there is ready access to medical images during consultations in secondary care health settings, but it is not normal practice for GPs, working in the community, to access their patient's images, even if theoretically possible. ${ }^{325}$ In primary care, generally it is only the written report of the image that is available and accessed in the consultation; however, one of our recruiting general practices was unusual in having well established, direct access to a community-based imaging facility (digital X-ray, dual energy X-ray absorptiometry (DXA) and MRI).

\section{Unanswered questions and future research}

The clinical encounter takes place, usually, in a dyadic form: in the present study, we queried only one half of the dyad with respect to the experience of viewing or not viewing a particular image. These physician's own point of view, his or her own reasons for deciding 'to share or not to share', remain opaque to us, reported if at all only by conjecture or hearsay on the part of our research participants. An investigation involving both halves of the pair would be a very useful addition to the project and build on the work we have already done with radiologists and GPs about sharing images with their patients. ${ }^{3}$

Another, almost completely unexplored component of medical imaging is the role of the technician or technologist: the individual who makes the image. Some of our participants reported significant encounters with the technician, both in terms of the experience of producing the image, and in terms of learning something of the results. Current guidelines regarding patienttechnician interactions allow for leeway depending on the seniority and position of the technician. Further exploration of the technician's role regarding patient viewing of images would be of interest.

In conclusion, for some patients the possibility of shared viewing of their own diagnostic images can be powerful and resonant experience in a variety of ways, including both better understanding of pain, or other sensations associated with diagnosis, and building a stronger alliance between doctor and patient. The nature and form of our data collection preclude giving a prescribed course of action regarding the showing or not showing images to particular patients, but we can say that an open and frank discussion of the possibility of such sharing is recommended. Further, we hope our 
work stimulates discussion among clinicians who will be increasingly faced with the opportunity to share visual evidence of health and disease with their patients.

Contributors LEC, FH and HES developed the study idea and method. LEC conducted the interviews and drafted the paper. LEC and HES read and coded the transcripts and interpreted the data. HES and FH provided constructive feedback on all versions of the manuscript. HES is the guarantor.

Funding This research received no specific grant from any funding agency in the public, commercial or not-for-profit sectors.

Competing interests None.

Ethics approval Ethical approval for the study was granted by the South East Coast Research Ethics Committee (Reference number 09/H1102/105).

Provenance and peer review Not commissioned; externally peer reviewed.

Data sharing statement No additional data are available.

Open Access This is an Open Access article distributed in accordance with the Creative Commons Attribution Non Commercial (CC BY-NC 3.0) license, which permits others to distribute, remix, adapt, build upon this work noncommercially, and license their derivative works on different terms, provided the original work is properly cited and the use is non-commercial. See: http:// creativecommons.org/licenses/by-nc/3.0/

\section{REFERENCES}

1. Department of Health. Imaging and radiodiagnostics [archived material for 2010-2011]. 2012. http://www.dh.gov.uk/en/ Publicationsandstatistics/Statistics/Performancedataandstatistics/ HospitalActivityStatistics/DH_077487 (accessed 5 Apr 2013).

2. Edwards J, Harvey P, Wade P. Technologized images, technologized bodies (page 20). In: Edwards J, Harvey P, Wade P, eds. Technologized images, technologized bodies. New York: Berghahn Books, 2010: 1-36.

3. Carlin L, Smith H, Henwood F, et al. Double vision: an exploration of radiologists' and general practitioners' views on using Picture Archiving and Communication Systems (PACS). Health Informat $J$ 2010;16:75-86.

4. Blaxter M. The case of the vanishing patient? Image and experience. Sociol Health IIIn 2009;31:1-17.

5. Mol A. Body multiple: ontology in medical practice. Durham, NC: Duke University Press, 2002.

6. Radstake M. Visions of illness: an endography of real-time medical imaging. Maastricht University, 2007.

7. Kaufert $P$. Screening the body: the pap smear and the mammogram. In: Lock M, Young A, Cambrosio A. eds Living and working with the new medical technologies. Cambridge: Cambridge University Press, 2000: 165-83.

8. Sandelowski M. Separate, but less unequal: fetal ultrasonography and the transformation of expectant mother/fatherhood. Gender Soc 1994;8:230-45.

9. Sandelowski M. Channel of desire: fetal ultrasonography in two use contexts. Qual Health Res 1994;4:262-80.

10. Bricker L, Garcia J, Henderson J, et al. Ultrasound screening in pregnancy: a systematic review of the clinical effectiveness, cost-effectiveness and women's views. Health Technol Assess 2000;4:i-vi, 1-193.

11. Mitchell LM. Baby's first picture: ultrasound and the politics of fetal subjects. Toronto: University of Toronto Press, 2001.

12. Green E, Griffiths F, Thompson D. 'Are my bones normal doctor?' The role of technology in understanding and communicating health risks for midlife women. Sociol Res Online 2006;11:24.

13. Reventlow SD. Perceived risk of osteoporosis: restricted physical activities? Scand J Prim Health Care 2007;25:160-5.

14. Reventlow SD, Hvas L, Malterud K. Making the invisible body visible. Bone scans, osteoporosis and women's bodily experiences. Soc Sci Med 2006;62:2720-31.

15. Reventlow SD, Overgaard IS, Hvas L, et al. Metaphorical mediation in women's perceptions of risk related to osteoporosis: a qualitative interview study. Health Risk Soc 2008;10:103-15.

16. Neergaard MA, Olesen F, Andersen RS, et al. Qualitative description-the poor cousin of health research? BMC Med Res Methodol 2009;9:52.

17. Palmer J. Seeing and knowing: ultrasound images in the contemporary abortion debate. Feminist Theory 2009;10:173-89.

18. Griffiths F, Bendelow G, Green E, et al. Screening for breast cancer: medicalization, visualization and the embodied experience. Health 2010;14:653-68.

19. Ogden J, Heinrich M, Potter C, et al. The impact of viewing a hysteroscopy on a screen on the patient's experience: a randomised trial. BJOG 2009;116:286-93.

20. Cohn S. Picturing the brain inside, revealing the illness outside: a comparison of the different meanings attributed to brain scans by scientists and patients. In: Edwards J, Harvey P, Wade P, eds. Technologized images, technologized bodies. New York: Berghahn Books, 2010: 65-84.

21. Van Dijck J. The transparent body: a cultural analysis of medical imaging. Seattle: University of Washington Press, 2005.

22. Flynn B. Maurice Merleau-Ponty. The Stanford Encyclopedia of Philosophy (Fall 2008 Edition), Edward N. Zalta (ed.), The Petaphysical Research Lab, CSLI, Stanford. http://plato.stanford. edu/archives/fall2008/entries/merleu-ponty/

23. Merleau-Ponty M. Phenomenology of perception. London: Routledge, 2002 [1945].

24. Cohn S. Making objective facts from intimate relations: the case of neuroscience and its entanglements with volunteers. History Hum Sci 2008;21:86-103.

25. Cherryman $\mathrm{G}$. Imaging in primary care. $\mathrm{Br} \mathrm{J}$ Gen Pract 2006;56:563-4. 